\title{
Sea lice infestation level alters salmon swimming depth in sea-cages
}

\author{
Samantha Bui ${ }^{1, *}$, Frode Oppedal $^{2}$, Lars Stien$^{2}$, Tim Dempster $^{1}$ \\ ${ }^{1}$ Sustainable Aquaculture Laboratory-Temperate and Tropical (SALTT), School of BioSciences, University of Melbourne, \\ Victoria 3010, Australia \\ ${ }^{2}$ Institute of Marine Research, Matredal 5984, Norway
}

\begin{abstract}
Host-parasite systems are often characterised by a co-evolutionary arms race, with avoidance behaviour being the first line of defence for hosts. In aquatic ecosystems, the rapid rise of fish farming has elevated host abundance, altering the context of host-parasite interactions. Behavioural defences in host fish may adapt to combat infection pressure in the captive environment. We tested whether farmed Atlantic salmon Salmo salar altered their swimming depth in response to the ectoparasitic sea louse Lepeophtheirus salmonis. Parasite loads were manipulated on individual fish, which were implanted with internal tags that recorded swimming depth. During daylight hours, salmon exhibited identical swimming depths irrespective of parasite load. However, fish with higher parasite loads (12-18 lice fish ${ }^{-1}$ ) swam deeper at nighttime, compared to fish with no or moderate parasite loads $\left(0-6\right.$ lice fish $\left.{ }^{-1}\right)$. As infective sea louse copepodids are concentrated near the surface, our results suggest that the preference for deeper water in fish with higher parasite loads is an avoidance mechanism to prevent further infestation. Host behavioural responses to parasites are predicted to shift with changes to the system and artificial selection of host phenotypes; our study provides the first evidence of a parasite avoidance response in salmon held in sea-cages.
\end{abstract}

KEY WORDS: Salmonid $\cdot$ Caligid $\cdot$ Sea lice $\cdot$ Behaviour $\cdot$ Depth distribution

\section{INTRODUCTION}

Behaviours within host-parasite systems may develop as part of the co-evolutionary arms race played out within the context of selective forces in the environment (Moore 2002). Domestication of terrestrial livestock in recent times is believed responsible for a wide variety of changes to host-parasite systems, and these processes are now likely underway in aquatic ecosystems, due to the recent and rapid domestication of marine animals by industrial aquaculture (Duarte et al. 2007). Host-parasite systems existing prior to aquaculture are likely to diverge into parallel scenarios with the introduction of fish farming, representing the natural system and that experienced by the farmed animals. Accordingly, behavioural defences of hosts may shift towards effec-

\footnotetext{
*Corresponding author: samanthab@unimelb.edu.au
}

tive avoidance of parasites in their corresponding habitats.

Migrating wild Atlantic salmon Salmo salar swim at specific depths as they move through rivers and estuaries into coastal waters (Thorstad et al. 2012). Out-migrating post-smolt salmonids swim in the brackish upper 1-3 $\mathrm{m}$ when they first enter the marine environment (Plantalech-Manella et al. 2009), but swim deeper in the water column once they leave shallower near-shore areas (Davidsen et al. 2008). Although these behaviours have been largely attributed to orientation mechanisms that assist migration, predator avoidance, and the shift in physiological requirements to seawater, they are also likely to reduce encounter rates with parasites (Gjelland et al. 2014). The salmonid-specific sea louse parasite Lepeophtheirus salmonis requires high-salinity water for opti-

(C) The authors 2016. Open Access under Creative Commons by Attribution Licence. Use, distribution and reproduction are unrestricted. Authors and original publication must be credited. 
mal survival and development (Bricknell et al. 2006) and concentrate beneath the brackish layer in estuaries or coastal areas (Heuch 1995). The freeswimming copepodid stage migrates vertically to avoid water $<27 \mathrm{psu}$, but is otherwise positively phototactic and orients towards the surface during daylight (Heuch 1995, Bricknell et al. 2006). High densities of attached sea lice incur heavy physiological fitness costs to salmon (Wagner et al. 2008) that can impair migratory performance. Within this wild salmonid host-parasite system, hosts must trade-off behaviours that drive survival from predators, promote successful migration and avoid parasite infestation (Thorstad et al. 2012).

With the introduction of intensive salmon farming in coastal waters, the ecology of the host (Gross 1998) and epidemiology of the parasite (Tully \& Nolan 2002) has shifted. Salmon are now present in coastal waters throughout the year in high abundance, providing positive conditions for increased transmission and virulence of parasites (Mennerat et al. 2010, Kennedy et al. 2016). L. salmonis are the most problematic parasite in salmon aquaculture across almost all salmon farming countries in the northern hemisphere (Costello 2006), causing farm production losses and depressing populations of wild salmon in areas of intensive aquaculture due to proliferation within farms and discharge to the wider environment (Costello 2009). L. salmonis progress through generations at a faster rate than salmon, and populations have exhibited occurrences of localised evolutionary change with regards to resistance to chemotherapeutants and virulence (Mennerat et al. 2012, Besnier et al. 2014). However, over 11 generations of selective breeding (Gjedrem et al. 2012), salmon used as broodstock will have been exposed to increasing infection pressure for the $2-3 \mathrm{yr}$ it takes to grow to breeding size. Farmed salmon are now subject to infection pressure throughout the year and have limited opportunity to select low-infection-risk areas, such as low-salinity habitats, in response to sea lice prevalence in the water or infection status. It is thus possible that behavioural adaptations to avoid infestation may have developed during this time scale.

Atlantic salmon in sea-cages follow a similar diurnal pattern of behaviour as wild salmon where they swim deeper during the day and shallower at night in thermally unstratified water (Oppedal et al. 2011). Although this can be altered by hunger status and environmental variables, it may also be influenced by infestation status. We hypothesised that farmed salmon would modify their swimming depths when heavily infested with $L$. salmonis. We tested this by manipulating parasite loads on individual fish and fitting them with pressure-recording tags to examine their depth distribution preference in the sea-cage. By experimentally manipulating parasite loads and holding salmon in the same sea-cage, all individuals were exposed to the same environmental conditions and natural infection pressure. Thus, any differences in behaviour could be attributed to experimental level of parasite loads.

\section{MATERIALS AND METHODS}

We tested if farmed Atlantic salmon altered their swimming depths under different parasite loads at an experimental farm facility in western Norway. Three weeks prior to the sea lice manipulation, a large group of salmon were captured using a cast net, and 23 salmon (average $[ \pm \mathrm{SE}]$ body mass: $3105 \pm 106 \mathrm{~g}$ ) were randomly selected from this group. They were anaesthetised (tricaine methanesulphate, Finquel, $10 \mathrm{~g} / 100 \mathrm{l}$ ), weighed and measured (in grams and centimetres, respectively), then surgically implanted with a data storage tag (DST-milli, $39.4 \times 13 \mathrm{~mm}$, $0.03 \%$ depth resolution and $\pm 0.4 \%$ accuracy, by StarOddi) into the body cavity. The incision site was closed with 3 independent sutures, and tissue adhesive (Histoacryl, B. Braun) was used to aid healing. The fish were then tagged externally with a T-bar anchor tag $(11 \mathrm{~cm}$, Hallprint) for identification and placed into a tank with natural seawater for recovery. This process took $<2 \mathrm{~min}$.

Once fish had recovered, they were returned to a small $\left(125 \mathrm{~m}^{3}\right)$ sea-cage for $3 \mathrm{wk}$ to ensure no adverse reaction to the tagging process. Subsequently, fish were recaptured and anaesthetised, and existing loads of adult $L$. salmonis on each individual were manipulated. Fish were randomly assigned to 1 of 4 lice levels: 'zero' ( 0 lice, $\mathrm{n}=5$ ), 'low' (6 lice, $\sim 0.0016$ lice $\mathrm{g}^{-1}, \mathrm{n}=6$ ), 'medium' (12 lice, 0.0032 lice $\mathrm{g}^{-1}, \mathrm{n}=5$ ) and 'high' (18 lice, 0.0045 lice $\mathrm{g}^{-1}, \mathrm{n}=7$ ). These levels are within the context of abundances observed on the farm. Previously attached lice were removed from each individual until the intended number of adult lice was reached. Only pre-adult and adult stages were present, and both adult male and female lice were retained. Parasite loads prior to experimental manipulation were between 20 and 28 lice, with no difference among the 4 lice level groups prior to lice reduction.

All of the DST tagged fish were placed in a single sea-cage. The cage was $12 \mathrm{~m}$ deep (volume: $\sim 1730 \mathrm{~m}^{3}$ ) and stocked with 3500 fish of approximately $3 \mathrm{~kg}$, 
originating from the same production cohort. Feed was supplied to the cage, via air-driven feed pipes, periodically throughout the daylight hours with the first and last feeding events at approximately 09:00 and 18:00 h. The tags registered pressure and logged at 2 min intervals for the $21 \mathrm{~d}$ sample period, after which the fish were retrieved and euthanised, and the tags were recovered. We then calculated the proportion of time spent by individuals at different depths and the average depth position for each individual from the DST data, across the experimental period.

Two main questions were addressed: (1) whether groups differed in the time spent below $4 \mathrm{~m}$ depth and (2) whether groups differed in their depth distribution during the day and night. Infection pressure was greater at the 0-4 m surface depths; thus, the percentage time (arcsine transformed; Crawley 2007) spent below $4 \mathrm{~m}$ was compared between control and low groups combined and between medium and high groups combined, using a Student's $t$-test. As the swimming depths of salmon typically differ between day and night due to the different lighting conditions (avoidance of light and surface during the day, with consideration for temperature and other environmental variables; Oppedal et al. 2011), we tested separately whether average swimming depth during daytime (10:00-17:00 h) and during nighttime (21:0005:00 h) were altered by infestation level. Dawn and dusk hours were not included in these averages to avoid unclear data from the salmon transitioning between day- and nighttime behaviour (Oppedal et al. 2011). Multiple regression incorporating parasite load and body mass were performed to determine the effect on depth, during daytime and nighttime. As the addition of body mass did not significantly add to the model ( $\mathrm{p}>0.24$ for both time periods, with reduced residual standard error and increased adjusted $\mathrm{R}^{2}$ values when removed), they were excluded from the model, leaving the depth and lice load terms in the regression analysis. Model assumptions were verified by assessing diagnostic plots, and the significance level was set at $\alpha=0.05$.

Environment at the site was monitored daily. Profiles of environmental variables (temperature, salinity, oxygen) were taken with a conductivity and depth sensory (CTD; SD204, SAIV AS) at a reference point near the cage, from 0 to $15 \mathrm{~m}$.

\section{RESULTS}

Over the 3 wk period, fish from all treatment groups were recorded swimming at all depths within the cage, with medium and high groups spending approximately 69 and $70 \%$ time below $4 \mathrm{~m}$, compared to 52 and $55 \%$ for the control and low groups $(p=0.007$; Fig. 1A). The school exhibited a regular diurnal vertical distribution pattern, whereby fish swam deeper during the day and shallower at night (Fig. S1 in the Supplement at www.int-res.com/ articles/suppl/q008p429_supp.pdf). Salmon across the treatment groups displayed almost identical depth preferences during daytime $\left(\mathrm{R}^{2}=0.02, F_{1,21}=\right.$ 0.39, $\mathrm{p}=0.54$; Fig. 1B); however, behaviours diverged at nighttime $\left(\mathrm{R}^{2}=0.29, F_{1,21}=8.68, \mathrm{p}=0.008\right.$; Fig. 1B). Comparing the average depths of individuals using 1-way ANOVA revealed no significant difference between the control and low groups $\left(F_{1,9}=\right.$ 0.36, $\mathrm{p}=0.56$ ) nor between the medium and high groups $\left(F_{1,10}=0.03, \mathrm{p}=0.87\right)$, but a clear difference between the combined medium and high groups and the combined control and low groups $\left(F_{1,21}=9.51, \mathrm{p}=\right.$ 0.006) was determined. Comparing control or low to medium or high groups individually gave only near significant $\mathrm{p}$-values $(0.05<\mathrm{p}<0.09)$.

The surrounding environmental conditions during the 3 wk experimental period lacked hydrographic structure, with no strong stratification of temperature or salinity (Fig. 2). Temperature ranged from 9.4 to $13.8^{\circ} \mathrm{C}$, while salinity ranged from 25.8 to $32.7 \mathrm{psu}$.

\section{DISCUSSION}

Our study provides evidence of a behavioural response in farmed salmon to Lepeophtheirus salmonis infestation, through changes in swimming depth with increasing parasite loads. The behaviour of all groups during daylight hours was almost identical, yet at night more highly parasitised salmon preferred waters deeper than $4 \mathrm{~m}$, in contrast to fish with fewer parasites that occupied shallower depths (Fig. 1B). Moreover, the shift in depth preference we observed was triggered at a relatively low total parasite load, far lower than estimated lethal thresholds ( $>0.75$ lice $\mathrm{g}^{-1}$ host mass for small juvenile salmon; Wagner et al. 2008). Changes in behaviour occurred between noninfested fish and fish with $<0.01$ adult lice $\mathrm{g}^{-1}$ for the highly infested treatment.

While our experiment does not enable us to determine what drove the response, the outcome of the behaviour was possibly reduced infestation with new copepodids. Infective sea louse copepodids concentrate at shallow depths (less than $\sim 10 \mathrm{~m}$; Penston et al. 2008, Johnsen et al. 2014) when no halocline is present (Costelloe et al. 1998, Costello 2006, 

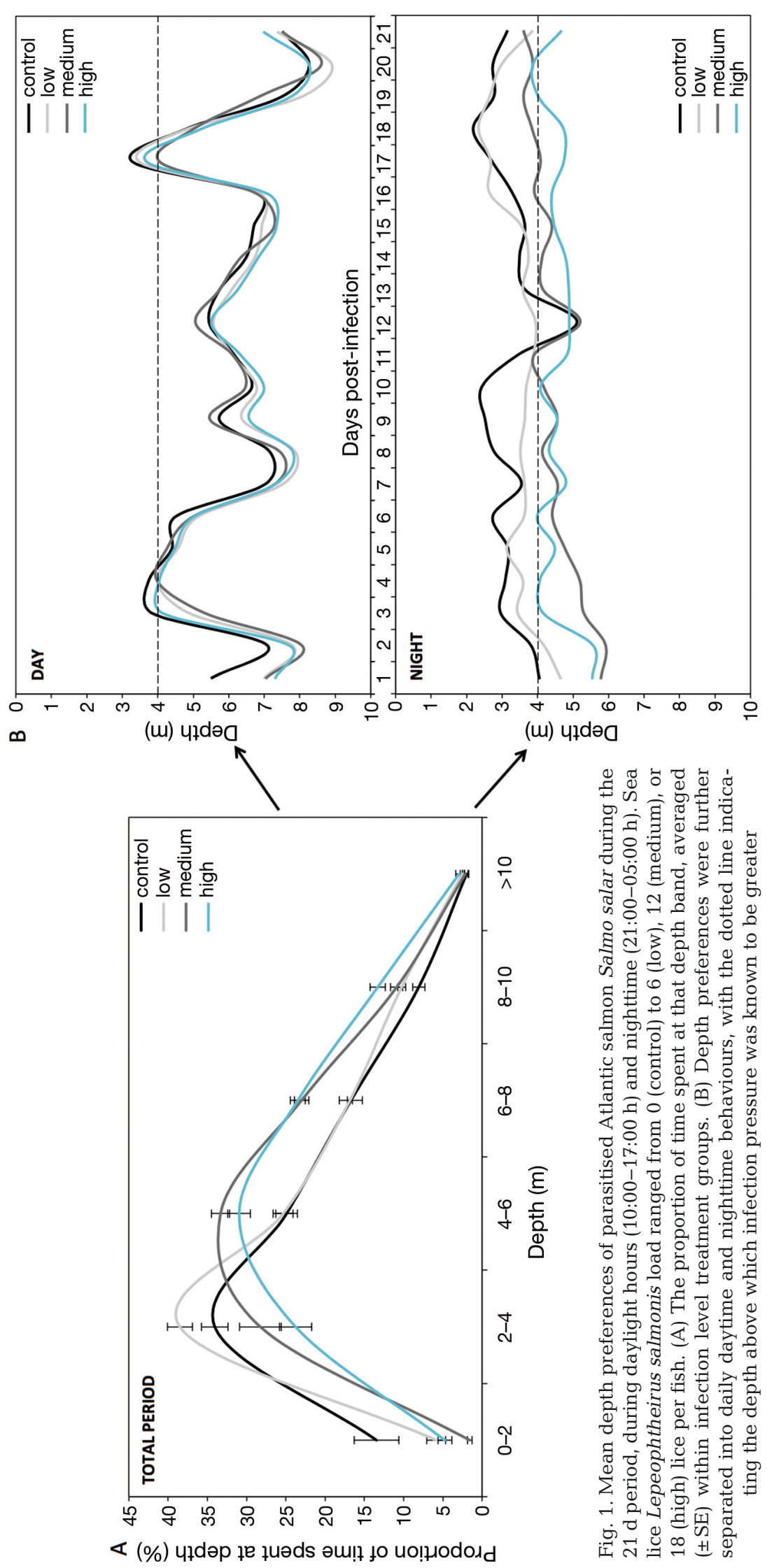

McKibben \& Hay 2004), to match the typical vertical distribution of their wild, free-swimming salmonid hosts (Heuch et al. 1995). At our site, where salinity was unstratified (Fig. 2), the greatest sea lice copepodid densities most likely occurred in the surface layers. Further, nauplii and infective copepodid stages have been reported to aggregate in shallow waters, with higher infestation rates in fish restricted between 0 and $4 \mathrm{~m}$ (Hervøy et al. 2003), and plankton samples demonstrating approximately $73 \%$ of nauplii within a seacage are found in the top $6 \mathrm{~m}$ (á Norði et al. 2016). An experiment running concurrently at the farm site during our experimental period confirmed that infective copepodids were most concentrated in the upper $4 \mathrm{~m}$ of the water column: salmon in 'snorkel' cages of the same dimension as cages used in this study, except with a roof that prevented access to $0-4 \mathrm{~m}$ depths (except via a chamber impermeable to seawater exchange), acquired $60-68 \%$ fewer new infestations than fish that could swim at 0-4 m (Fig. S2 in the Supplement; Stien et al. 2016). With the same stocking densities and fish size as our experimental salmon, the groups in unmanipulated sea-cages (also of the same dimensions as used in our study) exhibited distinct day and night swimming depths on most days, where their depths at night remained largely within 0-4 m (Fig. S1). When fish in the unmanipulated cages swam deeper and matched the depths of those in the snorkel cage, the levels of new infestations acquired (chalimus stages) were similar between the 2 groups (Fig. S3 in the Supplement; Stien et al. 2016). Hence, the deeper swimming by parasitised groups (medium and high) at night in our study indicates a reduced risk of further infestation. 


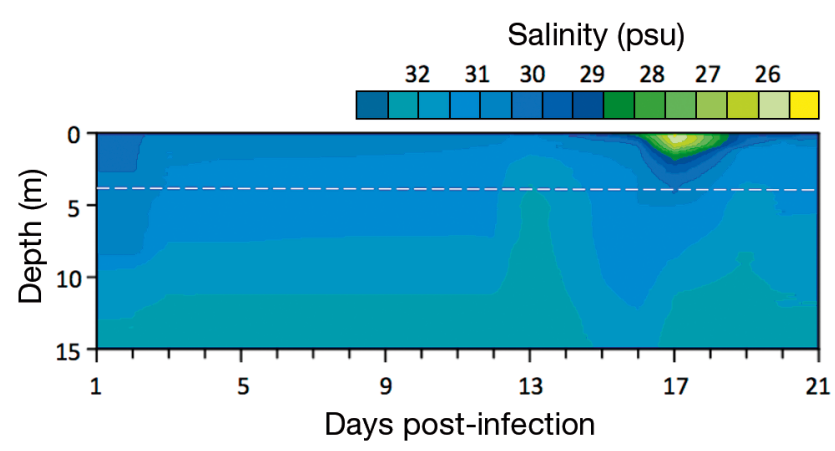

Fig. 2. The daily environmental salinity profile over the experimental period, taken at a reference point outside of the experimental cage. The dotted white line indicates the depth above which infection pressure was known to be greater

Current theories of vertical migration patterns of planktonic sea lice suggest a diurnal migration of up to $5 \mathrm{~m}$ (Heuch et al. 1995, Johnsen et al. 2014), whereby individuals actively move towards light during the day (i.e. at the surface) and sink lower at night (Heuch et al. 1995, Genna et al. 2005); however, there have been no recent field observations of this activity. In our study, copepodids at night may have sunk slightly, but still remained in the upper $4 \mathrm{~m}$ of the water column. If the highly parasitised treatment group was indeed avoiding further risk of infestation, this would match the depth distribution pattern of fish we observed (Fig. 1B), whereby all treatment groups swam below $4 \mathrm{~m}$ during daylight, but medium and highly infested fish remained deep at nighttime compared to control and low fish.

Trials conducted in laboratory settings show that light levels are important for attachment success (Novales Flamarique et al. 2000, Browman et al. 2004, Genna et al. 2005); however, little is known about the infection success rate of copepodids on Atlantic salmon in situ in darkness. Infection challenges in tanks have previously shown a maximum of 8-16\% attachment success in darkness on juvenile pink salmon Onchorynchus gorbuscha (with infection pressures of 25-100 copepodids fish ${ }^{-1}$; Jones et al. 2008), and 1-6\% attachment success for chum salmon Onchorynchus keta (155 or 271 copepodids fish $^{-1}$ infection pressure; Jones et al. 2006). The hostsearching and attachment behaviours of L. salmonis indicate that they rely on mechanical and olfactory indicators to trigger attachment rather than visual stimuli (Genna et al. 2005, Mordue [Luntz] \& Birkett 2009). Slow-swimming hosts are easier targets for attachment, and infection success is highest at moderate swimming speeds (Mordue [Luntz] \& Birkett
2009, Samsing et al. 2015), suggesting a compromise between visual and mechanical cues for hostsearching behaviour at nighttime. Although further research is required to understand sea lice infective behaviours in sea-cages at night, the vertical distribution of highly parasitised salmon away from the surface depths in our study infers an avoidance of zones with increased infection pressure.

With changes in the host-parasite landscape induced by intensive aquaculture, farmed fish experience infection pressure, but containment systems restrict their ability to display avoidance behaviours similar to wild salmonids (Thorstad et al. 2012), over a broad horizontal spatial scale. The vertical distribution of farmed fish in response to sea lice infestation that we documented contrasts to the vertical distribution of wild salmonids, which favour shallow depths when carrying a high parasite load (PlantalechManella et al. 2009, Gjelland et al. 2014). However, the preference for shallow depths in coastal waters when highly parasitised has been attributed to fish accessing a freshwater surface layer (Gjelland et al. 2014), which is lethal to new copepodid recruits within 3 h (Bricknell et al. 2006, Wright et al. 2016) and more advanced sea lice stages over days to weeks (Finstad et al. 1995, Stone et al. 2002, Connors et al. 2008). Except for Days 16-19 of the sample period, when lower salinity waters were prevalent in the upper $3 \mathrm{~m}$, the water column was fully saline and, therefore, the option of accessing a surface freshwater layer was unavailable to the heavily infested fish.

The novel conditions provided by farming impart new selection pressures on salmon, whereby individuals are released from predation risk and environmental cues that guide their migration (Nowak 2007). Thus, the spatial choices available to farmed salmon are driven by environmental conditions, such as temperature or salinity, and by husbandry practices, such as feed availability (Oppedal et al. 2011). Our study provides early evidence that parasite pressure is another factor that farmed salmon may respond to in choosing their preferred swimming depth. This knowledge contributes to our limited understanding of host-parasite behavioural interactions between Atlantic salmon and L. salmonis. Future studies should test the efficacy of depth preference in avoiding new infestations and also confirm whether this behaviour occurs under different environmental conditions (e.g. sites with brackish surface layers) and across seasons. Avoidance behaviours could be encouraged in salmon aquaculture by employing submerged lights which move the swimming depth of salmon away 
from parasite-risky surface waters (Hevrøy et al. 2003, Juell \& Fosseidengen 2004, Bui et al. 2013, Føre et al. 2013, Stien et al. 2014, Wright et al. 2015), and promote the prevention of sea lice infestation in sea-cages.

Acknowledgements. We thank Pascal Klebert (SINTEF) for providing the DST tags, and Jan Erik Fosseidengen, Gunnar Didriksen and Velemir Nola at Austevoll Research Farm (IMR, Norway) for their technical support. We thank Ben Phillips (University of Melbourne) for his comments on the manuscript. Funding was provided by a Norwegian Seafood Research Fund grant (F.O., L.S. and T.D., 900884) and an Australian Research Council Future Fellowship grant (T.D.).

\section{LITERATURE CITED}

á Norði G, Simonsen K, Patursson Ø (2016) A method of estimating in situ salmon louse nauplii production at fish farms. Aquacult Environ Interact 8:397-405

Besnier F, Kent M, Skern-Mauritzen R, Lien S and others (2014) Human-induced evolution caught in action: SNParray reveals rapid amphi-Atlantic spread of pesticide resistance in the salmon ecotoparasite Lepeophtheirus salmonis. BMC Genomics 15:937

Bricknell IR, Dalesman SJ, O'Shea B, Pert CC, Mordue Luntz AJ (2006) Effect of environmental salinity on sea lice Lepeophtheirus salmonis settlement success. Dis Aquat Org 71:201-212

Browman HI, Boxaspen K, Kuhn P (2004) The effect of light on the settlement of the salmon louse, Lepeophtheirus salmonis, on Atlantic salmon, Salmo salar L. J Fish Dis 27:701-708

Bui S, Oppedal F, Korsøen ØJ, Dempster T (2013) Modifying Atlantic salmon behaviour with light or feed stimuli may improve parasite control techniques. Aquacult Environ Interact 3:125-133

Connors BM, Krkošek M, Dill LM (2008) Sea lice escape predation on their host. Biol Lett 4:455-457

Costello MJ (2006) Ecology of sea lice parasitic on farmed and wild fish. Trends Parasitol 22:475-483

Costello MJ (2009) The global economic cost of sea lice to the salmonid farming industry. J Fish Dis 32:115-118

Costelloe M, Costelloe J, O'Donohoe G, Coghlan NJ, Oonk M, Van der Heijden Y (1998) Planktonic distribution of sea lice larvae, Lepeophtheirus salmonis, in Killary Harbour, west coast of Ireland. J Mar Biol Assoc UK 78:853-874

Crawley MJ (2007) Proportion data. In: Crawley MJ (ed) The R book. Wiley, Chichester, p 569-591

Davidsen JG, Plantalech Manel-la N, Økland F, Diserud OH and others (2008) Changes in swimming depths of Atlantic salmon Salmo salar post-smolts relative to light intensity. J Fish Biol 73:1065-1074

Duarte CM, Marbá N, Holmer M (2007) Rapid domestication of marine species. Science 316:382-383

Finstad B, Bjørn PA, Nilsen ST (1995) Survival of salmon lice, Lepeophtheirus salmonis Krøyer, on Arctic charr, Salvelinus alpinus (L.), in fresh water. Aquacult Res 26:791-795

Føre M, Dempster T, Alfredsen JA, Oppedal F (2013) Modelling of Atlantic salmon (Salmo salar L.) behaviour in sea-cages: using artificial light to control swimming depth. Aquaculture 388-391:137-146

Genna RL, Mordue W, Pike AW, Mordue (Luntz) AJ (2005) Light intensity, salinity, and host velocity influence presettlement intensity and distribution on hosts by copepodids of sea lice, Lepeophtheirus salmonis. Can J Fish Aquat Sci 62:2675-2682

Gjedrem T, Robinson N, Rye M (2012) The importance of selective breeding in aquaculture to meet future demands for animal protein: a review. Aquaculture 350-353:117-129

Gjelland KØ, Serra-Llinares RM, Hedger RD, ArechavalaLopez P and others (2014) Effects of salmon lice infection on the behaviour of sea trout in the marine phase. Aquacult Environ Interact 5:221-233

Gross MR (1998) One species with two biologies: Atlantic salmon (Salmo salar) in the wild and in aquaculture. Can J Fish Aquat Sci 55(Suppl 1):131-144

Hevrøy EM, Boxaspen K, Oppedal F, Taranger GL, Holm JC (2003) The effect of artificial light treatment and depth on the infestation of the sea louse Lepeophtheirus salmonis on Atlantic salmon (Salmo salar L.) culture. Aquaculture 220:1-14

Heuch PA (1995) Experimental evidence for aggregation of salmon louse copepodids (Lepeophtheirus salmonis) in step salinity gradients. J Mar Biol Assoc UK 75:927-939

Heuch PA, Parsons A, Boxaspen KK (1995) Diel vertical migration: a possible hostfinding mechanism in salmon louse (Lepeophtheirus salmonis) copepodids? Can J Fish Aquat Sci 52:681-689

Johnsen IA, Fiksen Ø, Sandvik AD, Asplin L (2014) Vertical salmon lice behaviour as a response to environmental conditions and its influence on regional dispersion in a fjord system. Aquacult Environ Interact 5:127-141

Jones S, Kim E, Dawe S (2006) Experimental infections with Lepeophtheirus salmonis (Krøyer) on threespine sticklebacks, Gasterosteus aculeatus L., and juvenile Pacific salmon, Oncorhynchus spp. J Fish Dis 29:489-495

Jones S, Kim E, Bennett W (2008) Early development of resistance to the salmon louse, Lepeophtheirus salmonis (Krøyer), in juvenile pink salmon, Oncorhynchus gorbuscha (Walbaum). J Fish Dis 31:591-600

Juell JE, Fosseidengen JE (2004) Use of artificial light to control swimming depth and fish density of Atlantic salmon (Salmo salar) in production cages. Aquaculture 233:269-282

Kennedy DA, Kurath G, Brito IL, Purcell MK, Read AF, Winton JR, Wargo AR (2016) Potential drivers of virulence evolution in aquaculture. Evol Appl 9:344-354

McKibben MA, Hay DW (2004) Distributions of planktonic sea lice larvae Lepeophtheirus salmonis in the inter-tidal zone in Loch Torridon, western Scotland in relation to salmon farm production cycles. Aquacult Res 35:742-750

Mennerat A, Nilsen F, Ebert D, Skorping A (2010) Intensive farming: evolutionary implications for parasites and pathogens. Evol Biol 37:59-67

Mennerat A, Hamre L, Ebert D, Nilsen F, Dávidová M, Skorping A (2012) Life history and virulence are linked in the ectoparasitic salmon louse Lepeophtheirus salmonis. J Evol Biol 25:856-861

Moore J (2002) Parasites and the behavior of animals. Oxford University Press, New York, NY

Mordue (Luntz) AJ, Birkett MA (2009) A review of host finding behaviour in the parasitic sea louse, Lepeophtheirus salmonis (Caligidae: Copepoda). J Fish Dis 32:3-13 
Novales Flamarique I, Browman HI, Belanger M, Boxaspen K (2000) Ontogenetic changes in visual sensitivity of the parasitic salmon louse Lepeophtheirus salmonis. J Exp Biol 203:1649-1657

Nowak BF (2007) Parasitic diseases in marine cage culture-an example of experimental evolution of parasites? Int J Parasitol 37:581-588

Oppedal F, Dempster T, Stien L (2011) Environmental drivers of Atlantic salmon behaviour in sea-cages: a review. Aquaculture 311:1-18

Penston MJ, Millar CP, Zuur A, Davies IM (2008) Spatial and temporal distribution of Lepeophtheirus salmonis (Krøyer) larvae in a sea loch containing Atlantic salmon, Salmo salar L., farms on the north-west coast of Scotland. J Fish Dis 31:361-371

Plantalech-Manella N, Thorstad EB, Davidsen JG, Økland F, Sivertsgård R, McKinley RS, Finstad B (2009) Vertical movements of Atlantic salmon post-smolts relative to measures of salinity and water temperature during the first phase of the marine migration. Fish Manage Ecol 16:147-154

Samsing F, Solstorm D, Oppedal F, Solstorm F, Dempster T (2015) Gone with the flow: current velocities mediate parasitic infestation of an aquatic host. Int J Parasitol 45:559-565

Stien LH, Fosseidengen JE, Malm ME, Sveier H, Torgersen T, Wright DW, Oppedal F (2014) Low intensity light of different colours modifies Atlantic salmon depth use. Aquacult Eng 62:42-48

Editorial responsibility: Ian Fleming,

St. John's, Newfoundland and Labrador, Canada
Stien LH, Dempster T, Bui S, Glaropoulos A, Fosseidengen JE, Wright DW, Oppedal F (2016) 'Snorkel' sea lice barrier technology reduces sea lice loads on harvest-sized Atlantic salmon with minimal welfare impacts. Aquaculture 458:29-37

Stone J, Boyd S, Sommerville C, Rae GH (2002) An evaluation of freshwater bath treatments for the control of sea lice, Lepeophtheirus salmonis (Krøyer), infections in Atlantic salmon, Salmo salar L. J Fish Dis 25: 371-373

Thorstad EB, Whoriskey F, Uglem I, Moore A, Rikardsen AH, Finstad B (2012) A critical life stage of the Atlantic salmon Salmo salar: behaviour and survival during the smolt and initial post-smolt migration. J Fish Biol 81:500-542

Tully O, Nolan DT (2002) A review of the population biology and host-parasite interactions of the sea louse Lepeophtheirus salmonis (Copepoda: Caligidae). Parasitology 124:165-182

Wagner GN, Fast MD, Johnson SC (2008) Physiology and immunology of Lepeophtheirus salmonis infections of salmonids. Trends Parasitol 24:176-183

Wright DW, Glaropoulis A, Solstorm D, Stien LH, Oppedal F (2015) Atlantic salmon Salmo salar instantaneously follow vertical light movements in sea cages. Aquacult Environ Interact 7:61-65

Wright DW, Oppedal F, Dempster T 2016 (in press) Earlystage sea lice recruits on Atlantic salmon are freshwatersensitive. J Fish Dis, doi: 10.1111/jfd.12452

Submitted: December 22, 2015; Accepted: June 24, 2016

Proofs received from author(s): August 5, 2016 